\title{
How Important are the International Financial Market Imperfections for the Foreign Exchange Rate Dynamics: A Study of the Sterling Exchange Rate
}

\begin{abstract}
The UK has been a net debtor over the past two decades and the sterling exchange rates are sensitive to any chaos that might occur in the financial market. This paper examines the importance of the international financial imperfections in the sterling exchange rate dynamics. We build a small open economy DSGE model with the constrained international financial institutions that intermediate capital flows, and derive tractable analytical solutions. The constraint works to introduce a wedge between lending and borrowing rates, which compensates financiers for their currency risk-taking. The model has been estimated by using a simulation-based Indirect Inference approach, which provides a natural framework for testing the hypothesis implied by the model. We find that the model cannot be rejected by the UK data. Shocks to financial forces are the main driving forces behind the large and sudden depreciation of the Sterling exchange rates in the aftermath of the collapse of Lehman Brothers and the Brexit vote. Furthermore, the optimal policy rules have been proposed.
\end{abstract}

Keywords: Small open economy DSGE model, International financial imperfections, Sterling exchange rates, Indirect Inference, Crisis, Policy rules

JEL classification: E63, F31, F34, F41, F47

\section{Introduction}

A massive sterling depreciation during the period of global financial crisis fuelled interest in the relationship between financial markets and the sterling exchange rate movements. The UK has recorded a net liability position since 1994 (Whittard, 2012), and it needs financing from abroad. 
Large-scale capital flows mostly are intermediated by international financial institutions, which profit often by taking the other side resulting from imbalances in currency demands due to both trade and financial flow. As a net debtor country, the UK generates a long exposure for financiers to their currencies. The sterling exchange rate would be sensitive to any chaos that might occur in the financial markets.

The conventional assumption of the frictionless international financial market implies that financiers take infinite positions whenever there is a nonzero expected excess return in the currency market. However, this it at odds with the empirical findings of currency risk premium (see Bilson(1981), Fama (1984), Engel (1996, 2014)). There are extensive debates on financial frictions and their implications for exchange rates. A recent notable example is the two-country model of Gabaix and Maggiori (2015), who assume that financial intermediaries require compensation for absorbing any imbalance between demand and supply of assets denominated in different currencies. This harks back to that of the portfolio balance approach (Kouri, 1976) of the exchange rate determination on the imperfect capital substitutability.

The central issue, in our view, is how important are the financial market imperfections for the sterling exchange rate dynamics. The paper attempts to answer the question by establishing a small open economy dynamic stochastic general equilibrium (DSGE) model in which financial imperfections take centre stage, and evaluating its fit as well as power to explain the UK data ${ }^{1}$ The way of modelling financial imperfections is inspired by Gabaix and Maggiori (2015). In this framework, the international financier is constrained to intermediate capital flows between home country and the rest of the world because of its balance sheet risk and limited risk bearing capacity. This limited commitment constraint works to introduce a wedge between lending and borrowing rates, which compensates financiers for their currency risk-taking. Then, we take the model directly to the UK data, and estimate the coefficient of financiers risk bearing

\footnotetext{
${ }^{1}$ It may have various explanations / theories of the sterling exchange rate dynamics. We do not rule out other possible explanations, such as adjustment mechanism; Broadbent (2017) pointed out towards adjustment of FX market to the possibility of Brexit. However, our concern is to establish the basic ability of the flexprice Real Business Cycle model with international financial imperfections to provide explanatory power.
} 
capacity using Indirect Inference techniques. Moreover, the model's implied causal relationship between the financial market imperfections and exchange rate dynamics is formally tested for its closeness to the UK experience.

Our main findings are as follows. Evidence from Indirect Inference tests show that our model fits the UK data behaviour between 1975 and 2016. It implies that international financial sector imperfections are necessary for explaining the sterling exchange rate dynamics. Moreover, we show that financial market imperfections could act as amplifiers of external shocks on the sterling exchange rate and other key UK macroeconomic variables based on the framework. In addition, we provide empirical evidence that shocks to the financial forces made a major contribution to a sharp sterling depreciation at the end of 2008 and after the Brexit vote. Last but not least, we discuss implications of the framework for policymakers to improve the welfare.

Our paper is related to three broad streams of literature. First, we provide a tractable generalequilibrium framework for the determination of the sterling exchange rates in imperfect international financial markets. It contributes to the small set of literature on exchange rate modelling in the presence of frictions including Alvarez, Atkeson, and Kehoe (2002, 2009), Maggiori et al. (2014), Bruno and Shin (2014) and Gabaix and Maggiori (2015). Second, our results suggest another possible explanation for the literature exploring the sterling exchange rate dynamics during the EU referendum. For example, Plakandaras et al. (2016) who argue that most of the sudden depreciation of sterling exchange rate is based on the uncertainty caused by the Brexit, Nasir and Morgan (2018) who argue that the weakness of sterling is due to the weak external position of the UK' s economy and the further role played by the uncertainty surrounding Brexit, and Nasir and Simpson (2018) who conclude that the Brexit associated sharp depreciation of sterling has significant implications for the UK' s external and price stability. Third, the paper also add a new empirical finding to a growing literature on resolving the exchange rate disconnect puzzle and the uncovered interest rate puzzle (Obstfeld and Rogoff, 2000). International financial intermediaries could be the source of financial shocks that distort exchange rates.

The paper is organized as follows. Section 2 describes the model. We estimate the baseline 
model using method of Indirect Inference. Also, all aspects of the baseline model are tested when testing for the financial imperfection in Section 3. Section 4 empirically analyses sterling exchange rate dynamics during the financial disruptions. Policy implications are the subject of Section 5. Section 6 concludes. The method of Indirect Inference, some peripheral technical derivations and data descriptions are delayed to Appendix.

\section{The Model}

The core framework is the Real Business Cycle model of a small open economy without the assumption of nominal rigidities developed by Uribe and Schmitt-Grohe (2016) To this, we add risk-averse international financial intermediaries that facilitate international assets transactions between the home country and the rest of the world. An agency problem constrains the ability of global financial intermediaries to absorb imbalances between the demand and supply of bonds denominated in different currencies arising from international trades. Thus, they require a currency risk premium proportional to the size of their currency exposures.

Consider an infinite periods world economy. Time is discrete and indexed by $t \in\{0, \infty\}$. The world economy is inhabited by a small open domestic economy and by the rest of the world. Goods are tradable among all countries, and there is a single industry and one broad type of consumption good traded at the global leve ${ }^{3}$. Both the domestic economy and the rest of the world can issue a risk-free one-period bond. We assume that the international financial market imperfection is caused by a binding international credit constraint. This constraint captures the relevant market practice in financial institutions whereby risk taking is limited not only by the overall size of position, but also by the risk-bearing capacities.

2 Meenagh et al. (2009) argued that the degree of nominal rigidities varies with changes in monetary regime. To avoid the issue of structure breaks, we choose a flexible price model rather than the model with nominal rigidities as an appropriate backdrop and focus on the real term behaviours of the economy. Although rigidities do not enter the transmission mechanisms in our model but implicitly enter into the error terms

${ }^{3}$ Non-traded goods are included already in home goods in this standard model. This formulation of the consumption basket can be also found in the open economy literature, such as Adolfson et al. (2007) and Meenagh et al (2010) 
The basic ingredients of the model are characterised in the following.

\subsection{Representative Household Problem}

The domestic economy is populated by an infinite number of identical households with preferences described by the utility function,

$$
E_{0} \sum_{t=0}^{\infty} \beta^{t} U\left(C_{t}, N_{t}\right)
$$

where $C_{t}$ denotes consumption, $\beta \in(0,1)$ is the subjective discount factor, the symbol $E_{0}$ denotes the expectation operator conditional on the information available at period $0 . U($.$) is a period$ constant relative risk aversion (CRRA) utility function which takes the following additively separable form,

$$
U\left(C_{t}, N_{t}\right)=\omega_{0} \varepsilon_{t}^{r} \frac{C_{t}^{1-\gamma_{C}}}{1-\gamma_{C}}-\left(1-\omega_{0}\right) \varepsilon_{t}^{N} \frac{N_{t}^{1+\gamma_{N}}}{1+\gamma_{N}}
$$

Households enjoy utility from goods consumption, $C_{t}$, while they receive dis-utility from labour supply, $N_{t} \cdot \gamma_{C}>0$ is the Arrow-Pratt coefficient of relative risk aversion for consumption, and its reciprocal, $1 / \gamma_{C}$, measures the inter-temporal substitution elasticity between consumption in two consecutive periods. $\gamma_{N}$, which is greater than 0, is the inverse of Frisch labour supply elasticity. $\omega_{0}\left(0<\omega_{0}<1\right)$ is a preference weight of consumption in the utility function. $\varepsilon_{t}^{r}$ and $\varepsilon_{t}^{N}$ are preference shocks, which affect the inter-temporal and the intra-temporal decision of households, respectively. Both shocks are assumed to follow a first-order autoregressive process with an i.i.d. error term.

This small open economy model assumes that the domestic country has a single, perfectly competitive final goods sector, producing a version of the final good that is distinct from the product of the foreign country. It is a single-industry version of the Armington model Armington, 1969; see also Feenstra et al., 2014). Armington model assumes that home and foreign goods are differentiated purely due to their origin of production. Households decide how to di-

vide her consumption spending across the differentiated products - home produced goods $\left(C_{t}^{d}\right)$ 
and foreign produced goods $\left(C_{t}^{f}\right)$. These differentiated products yield utility to the household via a constant elasticity of substitution (CES) aggregator,

$$
\widetilde{C}_{t}=\left[\omega^{\frac{1}{\theta}}\left(C_{t}^{d}\right)^{\frac{\theta-1}{\theta}}+(1-\omega)^{\frac{1}{\theta}}\left(\varepsilon_{t}^{I M}\right)^{\frac{1}{\theta}}\left(C_{t}^{f}\right)^{\frac{\theta-1}{\theta}}\right]^{\frac{\theta}{\theta-1}}
$$

where $\widetilde{C}_{t}$ is the composite consumption utility index, $\omega$ is the weight of domestically produced goods, and $\theta>0$ is the elasticity of substitution between home and foreign goods ${ }^{4}, \varepsilon_{t}^{I M}$ is a random preference shock of home demand for foreign produced goods.

The domestic household maximises this composite utility index, given that an amount $C_{t}$ has been chosen for total expenditure, i.e.

$$
C_{t}=p_{t}^{d} C_{t}^{d}+Q_{t} C_{t}^{f}
$$

where $p_{t}^{d}$ denotes the domestic goods price level, $P_{t}^{d}$, relative to the general price level, $P_{t} 5^{5}$ $Q_{t}$ is the relative price of home and foreign countries' consumption basket. It is a unit free measure of the price of the foreign consumption goods $P_{t}^{F}$ relative to the general price level in home country $P_{t}$ defined as $Q_{t}=S_{t} P_{t}^{F} / P_{t}$, where $S_{t}$ is the nominal exchange rate and is given in terms of domestic currency needed to buy a unit of foreign currency. Intuitively, an increase in $Q_{t}$ can be thought of as a real exchange rate depreciation, as it implies a real depreciation of domestic goods on the world market and a rise in the competitiveness of domestic exports. We treat the consumption bundle as the numeraire and, consequently, its price equals 1 in the domestic currency. Given that, all prices in the budget constraint are expressed relative to the

\footnotetext{
${ }^{4}$ The value of $\omega$ is crucial since it describes the degree of home bias in preferences. $\omega>\frac{1}{2}$ implies a bias towards domestic produced tradable goods relative to imported goods from the rest of the world. Domestic produced goods and imported goods are perfect substitutes if $\theta$ approaches infinity; those goods are perfect complements if $\theta$ approaches zero. The degree of substitution between home-produced and imported goods may be affected by economic reasons, such as product quality or industry features, and also influenced by political variables and strategies.

${ }^{5}$ Given the agent's optimally chosen amount of $\mathrm{Ct}$ for the level-one utility maximisation, we can treat it as a parametric value and consider how that amount of the consumption bundle should break down between consumption of the domestic variety, $C_{t}^{d}$ and the foreign variety, $C_{t}^{f}$.
} 
general price level, $P_{t}$. Hence, in terms of the domestic currency, the unit cost of imported goods, $C_{t}^{f}$, is $Q_{t}$.

The domestic household chooses processes $\left\{C_{t}^{d}, C_{t}^{f}\right\}_{t=0}^{\infty}$ to maximise composite utility index (3) subject to the constraint that

$$
\widetilde{C}_{t} \leq C_{t},
$$

taking as given the relative prices $\left\{p_{t}^{d}, Q_{t}\right\}_{t=0}^{\infty}$

We can obtain the domestic demand for foreign produced goods (import equation),

$$
C_{t}^{f}=I M_{t}=(1-\omega) \varepsilon_{t}^{I M}\left(Q_{t}\right)^{-\theta} C_{t}
$$

by solving the composite utility index maximization problem, which is given in the Appendix D.1.

The domestic demand for home goods is positively affected by total consumption in the home country, $C_{t}$, and negatively by the price of domestic produced goods relative to the general price level, $p_{t}^{d}$; while domestic import depends positively on the total home consumption of goods, $C_{t}$, and negatively on the real exchange rate, $Q_{t}$.

We assume that each period the representative household supplies $N_{t}$ hours to the labour market and earns consumer real wage $\left(w_{t}\right)$, which is equal to the producer wage deflated by the consumer price index. The household finances his expenditure through labour income $\left(w_{t} N_{t}\right)$ and total profit income $\left(\Pi_{t}\right)$ received from the ownership of shares of domestic firms. And he can buy or sell financial instruments in the form of risk-free bonds issued by the domestic government and the rest of the world. To emphasise the currency mismatch that the international financial intermediary has to absorb, we assume that the home country only trades in its own currency bonds 7 . A risk-free bond issued by the rest of the world is intermediated by a representative

\footnotetext{
${ }^{6} \mathrm{At}$ the point of the maximum the constraint is binding, so that the consumption-equivalent utility, $\widetilde{C}_{t}$ (the variable that appears in Equation (3), is equal to the amount spent on consumption goods, $C_{t}$ that the variables appears in household's budget constraint (7).

${ }^{7}$ If this assumption was relaxed and domestic household was allowed to trade optimally foreign bonds, we would
} 
international financiei 8 .

Both financial instruments, $D_{t+1}, \widetilde{D_{t+1}}$, with time subscripts $t+1$ are the household' s debt positions with a unit price at $t$, and require one plus the rate of interest agreed at time $t$ in the following due period $(t+1) \sqrt[9]{ }$ He uses those funds to purchase consumption goods, $C_{t}$, and pays back the principal and interest on its outstanding domestic and foreign debts, $\left(1+r_{t-1}\right)$ and $\left(1+\widetilde{r_{t-1}}\right)$, respectively. Also, the household is taxed by a lump-sum transfer, $T_{t}$; marginal tax rates are not included in the model explicitly and appear implicitly in the error term of the labour supply equation.

The period-by-period budget constraint of the representative household is given by ${ }^{10}$

$$
C_{t}+D_{t}\left(1+r_{t-1}\right)+\widetilde{D_{t}}\left(1+\widetilde{r_{t-1}}\right)+T_{t}=w_{t} N_{t}+\Pi_{t}+D_{t+1}+\widetilde{D_{t+1}}
$$

The household chooses processes $\left\{C_{t}, N_{t}, D_{t+1}, \widetilde{D_{t+1}}\right\}_{t=0}^{\infty}$ to maximise his utility (Equation 11 ) and Equation (2) subject to his budget constraint (7) and no-Ponzi constraints of the forms,

$$
\begin{aligned}
& \lim _{j \rightarrow \infty} E_{t} \frac{D_{t+1+j}}{\prod_{j=0}^{j}\left(1+r_{j}\right)} \leq 0 \\
& \lim _{j \rightarrow \infty} E_{t} \frac{\widetilde{D_{t+1+j}}}{\prod_{j=0}^{j}\left(1+\widetilde{r_{j}}\right)} \leq 0,
\end{aligned}
$$

taking the processes $\left\{r_{t}, w_{t}, \widetilde{r_{t}}, \Pi_{t}, T_{t}\right\}_{t=0}^{\infty}$ and the initial conditions $D_{0}\left(1+r_{-1}\right)$ and $\widetilde{D_{0}}\left(1+\widetilde{r_{-1}}\right)$ as given. The conditions in Equation (8) and Equation (9) imply that debts do not grow faster than their corresponding interest rates. The full details of consumer's first order optimality conditions have been given in Appendix D.2.

recover the uncovered interest parity condition by deriving the consumer first order optimality conditions.

${ }^{8}$ Risk-free here refers to paying one unit of foreign general consumption basket in all states of the world.

${ }^{9} \widetilde{D_{t+1}}$ is denominated on home currency in order to derive a currency risk premium term in Section 2.4

${ }^{10} \mathrm{We}$ treat the consumption bundle, $C_{t}$ as the numeraire so that all prices are expressed relative to the general price level, $P_{t}$. In other words, the price of the aggregate real consumption basket equals 1 in the domestic currency, i.e. $C_{t}=\frac{P_{t} C_{t}}{P_{t}}$. 


\subsection{Relationship with the Rest of the World}

Given Equation (6) above, there exists a symmetric equation for the rest of the world which describes the foreign demand for domestic goods. Hence, this export equation for the home economy is

$$
E X_{t}=\left(1-\omega^{F}\right) \varepsilon_{t}^{E X}\left(Q_{t}\right)^{\theta^{F}} C_{t}^{F}
$$

where $E X_{t}$ denotes the foreign demand for domestic goods (export from domestic country to the rest of the world). $\omega^{F}, C_{t}^{F}$ and $\theta^{F}$ are the foreign equivalents to home bias, total consumption of goods and the elasticity of marginal substitution between domestic and imported goods, respectively. $\varepsilon_{t}^{E X}$ is the random preference shock to the foreign demand for domestic goods. The volume of export demand goes up when total consumption of goods in the rest of the world, $C_{t}^{F}$, increases. A depreciation of real exchange rate (a rise in $Q$ ) induces a rise in the competitiveness of domestic exports. Total consumption of goods in the rest of the world, $C_{t}^{F}$, is treated as an exogenous variable given by a first-order autoregressive process,

$$
\ln C_{t}^{F}=\rho_{C^{F}} \ln C_{t-1}^{F}+\eta_{C^{F}, t},
$$

where $\eta_{C^{F}, t}$ is an independent and identically distributed innovation.

\subsection{Representative Firm Problem}

The output of the economy is assumed to depend on a production function that combines labour and capital inputs. Firms operate in perfectly competitive product and factor markets. A representative firm hires labour, purchases new capital goods to produce an homogeneous final good using production technology given by

$$
Y_{t}=A_{t} N_{t}^{\alpha} K_{t}^{1-\alpha}
$$


where $A_{t}$ is a random productivity shock variable and reflects the state of technology. $Y_{t}$ is an output of the economy. $\alpha(0 \leq \alpha \leq 1)$ is the output elasticity of labour.

Capital evolves according to the following law of motion

$$
K_{t+1}=(1-\delta) K_{t}+I_{t}
$$

where $K_{t}$ is predetermined capital stock, $I_{t}$ is the firm's investment, and $\delta$ measures the depreciation rate.

Assuming free entry into the industry and a large number of firms operating under perfect competition. The firm maximises the present discounted value of profits,

$$
\pi_{0}=E_{0} \sum_{t=0}^{\infty} \beta^{t} \frac{\lambda_{t}}{\lambda_{0}}\left[Y_{t}-\left(\widetilde{w}_{t}+\varepsilon_{t}^{N^{d}}\right) N_{t}-I_{t}-\frac{\kappa}{2}\left(K_{t+1}-K_{t}\right)^{2}\right]
$$

subject to the constant-return-to-scale production technology and quadratic adjustment costs for capital, through its choices of $\left\{N_{t}, I_{t}\right\}_{t=0}^{\infty}$, taking prices $\left\{\widetilde{w}_{t}, \lambda_{t}\right\}_{t=0}^{\infty}$ and initial condition $K_{0}$ as given ${ }^{11} \lambda_{t}$ is a shadow price, and $\beta^{t} \lambda_{t} / \lambda_{0}$ represents the value assigned by households to contingent payments of goods in period $t$ in terms of units of goods in period $\mathrm{d}^{12} \kappa$ denotes a multiplicative constant affecting adjustment costs. $\varepsilon_{t}^{N^{d}}$ is the shock to the net rental cost of labour.

The first order conditions give the firm's demand for labour condition,

$$
N_{t}=\alpha \frac{Y_{t}}{\widetilde{w}_{t}+\varepsilon_{t}^{N^{d}}}
$$

\footnotetext{
${ }^{11}$ The real rental price of labour paid by the domestic firm, $\widetilde{w}_{t}$, is the nominal wage relative to the unit value of domestically produced goods. It is different from the real wage referred to the household problem, $w_{t}$.

$$
\widetilde{w}_{t}=\frac{w_{t}}{p_{t}^{d}}=\frac{w_{t}}{\left[\frac{1-(1-\omega) \varepsilon_{t}^{I M}\left(Q_{t}\right)^{1-\theta}}{\omega}\right]^{\frac{1}{1-\theta}}} .
$$

${ }^{12} \beta^{t} \lambda_{t}$ denotes the Lagrange multiplier associated with the sequential budget constraint 7
} 
and a non-linear difference equation in capital,

$$
K_{t+1}=-\frac{1}{\kappa}+K_{t}+\frac{1-\alpha}{\kappa\left(1+r_{t}\right)} \frac{E_{t} Y_{t+1}}{K_{t+1}}+\frac{1-\delta}{\kappa\left(1+r_{t}\right)}+\frac{E_{t} K_{t+2}-K_{t+1}}{1+r_{t}}-\frac{1}{\kappa} \varepsilon_{t}^{K}
$$

Equation (16) could be named as the demand for capital, and its non-linearity is caused by the quadratic capital adjustment costs that the firm faces. $\varepsilon_{t}^{K}$ represents the shock to the net rental cost of capital.

\subsection{International Financial Intermediary}

We follow the spirit of Gabaix and Maggiori (2015) to develop an open economy model with financial frictions in the intermediation process of international capital flows. Domestic households can freely trade domestic assets, i.e. $D_{t+1}$, however, they are constrained in their holdings of foreign assets. There is a unit mass of global financial firms in the global financial market, who can actively invest in bonds denominated in both of home currency and foreign currencies and are hence able to absorb any excess supply and demand of assets. Furthermore, financiers with no capital of their own face limited commitment constraints.

For simplicity, we assume that the financiers are owned by households from the rest of the world and the management of financial firms is a one-period job. At the end of each period, financiers pay their profits and losses out to the owners. The representative financier's balance sheet consists of $\widetilde{D_{t+1}}$ domestic currency, and $-\widetilde{D_{t+1}} / Q_{t}$ foreign currency, where $\widetilde{D_{t+1}}$ is the value in domestic currency of domestic currency-denominated bonds the financier is long of, and $-\widetilde{D_{t+1}} / Q_{t}$ the corresponding value in foreign currency of foreign currency-denominated bonds ${ }^{13}$. The subscript $t+1$ expresses the maturity date of those financial instruments, which are issued at time $t$.

Suppose that the expected value of his financial firms is generated by lending $\widetilde{D_{t+1}}$ to do-

\footnotetext{
${ }^{13}$ In the absence of a nominal side to the model, the currency means a claim to the numeraire of the economy; domestic currency-denominated or foreign currency-denominated mean values expressed in units of general consumption baskets in each economy.
} 
mestic households at the interest rate $\widetilde{r_{t}}$ and capturing corresponding funds $\widetilde{D_{t+1}} / Q_{t}$, from the rest of the world at the world interest rate $r_{t}^{f}$. It is given by

$$
V_{t}=E_{t}\left\{\beta \frac{\lambda_{t+1}}{\lambda_{t}}\left[\left(1+\widetilde{r_{t}}\right)-\left(1+r_{t}^{f}\right) \frac{Q_{t+1}}{Q_{t}}\right] \widetilde{D_{t+1}}\right\}
$$

Note that values are discounted using the factor $\beta \lambda_{t+1} / \lambda_{t}$, which is the value assigned by the financier to contingent payments of goods in period $t+1$ in terms of units of goods in period t. Since the financier pays back the principle to foreign countries one period later, the value of liability, $-\widetilde{D_{t+1}} / Q_{t}$ should be adjusted with the expected relative price at the maturity date $t+1$, that is, expected real exchange rate, $E_{t} Q_{t+1}$.

The financiers' borrowing process is subject to an agency friction that imposes a restriction on the size of the balance sheet of the financiers, which prevents perfect arbitrage between domestic-currency denominated bonds and foreign-currency denominated bonds. To take the role of limited financial risk-bearing capacity by the financiers, we assume that financiers can divert a portion $\Gamma_{t}\left|\widetilde{D_{t+1}} / Q_{t}\right|$ of the funds they intermediate in each period 14 Rational foreign lenders anticipate the incentives of the financier to divert funds and are willing to lend as long as the following constraint $(18)$ holds

$$
\frac{V_{t}}{Q_{t}} \geq\left|\widetilde{D_{t+1}}\right| \Gamma_{t}\left|\frac{\widetilde{D_{t+1}}}{Q_{t}}\right|
$$

where $\Gamma_{t}=\Gamma \varepsilon_{t}^{\Gamma} ; \Gamma_{t}$ is a function of financial shocks to financier' risk bearing capacity.

The left-hand side of Equation (18) measures the intermediary value in foreign currency, while the right-hand side is the total divertable funds, which is convex in $\widetilde{D_{t+1}}$. In addition, the value of the financier's financial firm is linear in the position $\widetilde{D_{t+1}}$, hence the constraint, Equation (18), always binds. The constraint limits the maximum position the financiers can take. The parameter of the financier's average risk bearing capacity, i.e. $\Gamma(\Gamma \geq 0)$, captures the

\footnotetext{
${ }^{14}$ In order to make economic sense the constraint must satisfy that $\Gamma_{t}\left|\widetilde{D_{t+1}} / Q_{t}\right| \leq 1$. That is, the global intermediary cannot steal more than 100 percent of the funds borrowed.
} 
ability of financiers to bear risks, and governs the debt elasticity of the country interest rate. $\varepsilon_{t}^{\Gamma}$ is the financial shock which alters the financiers' risk bearing capacity.

The representative financier chooses processes $\left\{\widetilde{D_{t+1}}\right\}_{t=0}^{\infty}$ to maximise the expected value of his financial firms, Equation (17) subject to his limited commitment constraint (18), taking as given the processes $\left\{\widetilde{r}_{t}, r_{t}^{f}, Q_{t}, \lambda_{t}\right\}_{t=0}^{\infty}$. We obtain

$$
\widetilde{D_{t+1}}=\frac{1}{\varepsilon_{t}^{\Gamma} \Gamma}\left[Q_{t}-\frac{\left(1+r_{t}^{f}\right)}{\left(1+r_{t}\right)} E_{t} Q_{t+1}\right]
$$

Equation (19) shows the financiers' downward sloping demand for domestic currency. Alternatively, it shows the supply of foreign credit converted in home currency intermediated by the global financier.

Intuitively, an increase in the value of $\Gamma$ leads to a decrease in the financiers' ability to carry the currency risk of their portfolio; in addition, their domestic asset demand curve becomes steeper due to the rise in the required compensation per unit of risk, and the global asset market tends to be more segmented. In particular, as the value of $\Gamma$ goes to infinity, then the demand for domestic bonds, $\widetilde{D_{t+1}}$ goes to 0 . In this case, the financiers are unable to take any position, put differently, they are unwilling to absorb any imbalance, for example, those caused by the trade flows. On the other hand, as the value of $\Gamma$ goes to 0 , then the financier is willing to trade (either borrow or lend) as much as possible in domestic currency-denominated and foreign currencydenominated bonds given any non-zero expected excess return in the global financial market. In this situation, uncovered interest parity holds, that is, assets from different countries have the same expected rate of return when they are converted into the same currency.

Equation (19) implies the determination of real exchange rate, which is

$$
Q_{t}=\frac{1+r_{t}^{f}}{1+r_{t}} E_{t} Q_{t+1}+\varepsilon_{t}^{\Gamma} \Gamma \widetilde{D_{t+1}}
$$

The behaviour of exchange rate and currency risk premium are linked to home country's external imbalances in a setting in which assets are imperfect substitutes. 
There are two distinct channels - interest rate differentials channel and currency risk-taking channel through net foreign debt (asset) positions which affect currency excess returns. By providing a simple and tractable specification for the credit constrained problem, we emphasise that the financier's demand function captures the feature of limits of arbitrage theory and the spirit of international financial intermediation.

\subsection{Government}

The government's sources of income are tax revenue collected from households, and the issuance of new government bonds maturing one period ahead, $-D_{t+1}$. Government's spending consists of goods of consumption, $G_{t}$, which is assumed to be non-productive and made up strictly of welfare transfers, and interest payments on government debt agreed at a previous period, $-r_{t-1} D_{t}$. The sequential budget constraint of the government is then given by

$$
T_{t}-D_{t+1}=G_{t}-D_{t}\left(1+r_{t-1}\right)
$$

where $T_{t}$ is a lump-sum tax, capturing the revenue effects of all tax instruments that affect the household. Government spending $G_{t}$ is treated as an exogenous variable given by the first-order autoregressive process,

$$
\ln G_{t}=\rho_{G} \ln G_{t-1}+\eta_{G, t} .
$$

\subsection{Market Clearing Conditions}

According to Walras' Law in general equilibrium theory, demand should be equal to supply in each market.

This leads to the following market clearing conditions in goods market for home country,

$$
Y_{t}=C_{t}+I_{t}+G_{t}+E X_{t}-I M_{t}
$$


We consider the fundamental balance-of-payments identity in the open economy,

$$
\widetilde{D_{t+1}}-\widetilde{D_{t}}=\widetilde{r_{t-1}} \widetilde{D_{t}}+I M_{t} Q_{t}-E X_{t}
$$

It says that the change in the country's net foreign debt position equals the repayment of foreign debt from the previous period and the net import.

\section{Testing the Model against the Data}

\subsection{Data}

The data included in this study were obtained from the first quarter of 1975 to the last quarter of 2016 because the UK has had floating exchange rates among its major trading partners since the early $1970 s^{15}$ In order to capture the effects of the financial disruption on exchange rates, we include data during the turbulent periods from early 2008 until early 2013 due to the global financial crisis and the European debt crisis, and from early 2016 until late 2016 because of the Brexit vote. In general, the UK has very low capital controls, little probability of default and deep markets in foreign exchange. Therefore, these factors narrow the possible explanations for exchange rate puzzles. A detailed description of the data used is given in the Appendix A.

\subsection{Model Estimation and Evaluation by the Method of Indirect Inference}

The model is estimated using the method of Indirect Inference which is set out in Appendix C. Table 1 shows the estimation results for the structural model. All parameters are allowed to change some way from their calibration apart from quarterly discount factor $(\beta)$, quarterly depreciation rate $(\delta)$, and output elasticity of labour $(\alpha)$ which are held fixed on theoretical grounds.

\footnotetext{
${ }^{15}$ It should be noted that the UK entered the European Exchange Rate Mechanism (ERM) in October 1990, but was forced to exit the programme within two years after the pound sterling came under major pressure from currency speculators. The ERM is based on the concept of fixed currency exchange rate margins, but with exchange rates variable within those margins. This is also known as a semi-pegged system.
} 
Table 1: Coefficient Estimates (1975Q1-2016Q4)

\begin{tabular}{|c|c|c|c|c|}
\hline Symbol & Definitions & Estimation & Calibration & Change $(\%)$ \\
\hline \multicolumn{5}{|c|}{ Households } \\
\hline 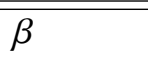 & a quarterly discount factor & 0.99 & 0.99 & fixed \\
\hline$\gamma_{C}$ & CRRA coefficient for consumption & 1.12 & 1.03 & 9 \\
\hline$\gamma_{N}$ & $\begin{array}{l}\text { the inverse of Frisch labour supply } \\
\text { elasticity }\end{array}$ & 1.35 & 1 & 35 \\
\hline$\omega$ & $\begin{array}{l}\text { a bias towards domestic produced } \\
\text { goods }\end{array}$ & 0.5 & 0.7 & -29 \\
\hline$\theta$ & $\begin{array}{l}\text { elasticity of substitution between home } \\
\text { and foreign goods }\end{array}$ & 2.74 & 1 & 174 \\
\hline$\theta^{F}$ & foreign equivalent of $\theta$ & 1.83 & 1 & 83 \\
\hline \multicolumn{5}{|l|}{ Firms } \\
\hline$\alpha$ & output elasticity of labour & 0.7 & 0.7 & fixed \\
\hline$\delta$ & a quarterly depreciation rate & 0.025 & 0.025 & fixed \\
\hline$\zeta_{1}$ & capital equation coefficients & 0.65 & 0.51 & 27 \\
\hline$\zeta_{2}$ & capital equation coefficients & 0.32 & 0.47 & -32 \\
\hline$\zeta_{3}$ & capital equation coefficients & 0.02 & 0.02 & 0 \\
\hline$\zeta_{4}$ & capital equation coefficients & 0.72 & 0.25 & 188 \\
\hline \multicolumn{5}{|c|}{ Financiers } \\
\hline $\bar{\Gamma}$ & financiers' risk bearing capacity & 0.3 & 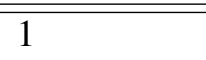 & $\overline{-70}$ \\
\hline
\end{tabular}

Iskrev $(2018$, p.2) states that "it is common practice in the empirical macroeconomic literature to mix estimation of some model parameters with calibration of others. The rationale behind this approach is either that some parameters are difficult to identify from available data, or that their values have been well-established elsewhere in the literature." We calibrated $\beta, \alpha$ and $\delta$ based on the standard empirical literature (see Smets and Wouters (2003)) ${ }^{16}$ On the international financial intermediary side, the global financiers' average risk-bearing capacity within 1975Q1 to 2016Q4 is estimated at 0.3, which implies the global financial market is imperfect and uncovered interest parity does not hold. To absorb imbalances caused by the international trade, financial intermediaries require risk premiums based on their risk-bearing capacities and balance sheets.

Indirect Inference provides a classical statistical inferential framework for judging whether

\footnotetext{
${ }^{16} \mathrm{We}$ are aware that mis-calibration could cause biased estimates of estimated parameters. However, we might expect that there would be little effect of those fixed parameters on the estimated parameter of the financier' $s$ risk bearing capacity which in the model is not functionally closely related to the fixed parameters.
} 
Table 2: Indirect Inference Test Results for the Financial Market Imperfection

\begin{tabular}{lll}
\hline & & Model Test Results \\
\hline Financiers' Risk Bearing Capacity & WALD $(\mathrm{Q}, \mathrm{r}, \mathrm{Y})$ & P-Value \\
\hline Estimated $(\Gamma=0.3)$ & 16.7250 & 0.3180 \\
Lower Bound $\left(\Gamma_{L}=0.05\right)$ & 27.6925 & 0.0510 \\
Upper Bound $\left(\Gamma_{U}=0.95\right)$ & 27.7381 & 0.0500 \\
\hline
\end{tabular}

a model with a particular set of parameters could have generated the behaviour found in a set of actual data. With the set of estimated coefficients, the test result presented in Table 2 suggests a strong non-rejection of the model with imperfect financial market at the 5\% significant level, with a p-value in excess of 0.05 . The Wald statistic based on observed data lies at around 68th percentile of the distribution of simulated estimates.

In order to further test the hypothesis of imperfect financial market against the UK data, we vary the coefficient $\Gamma$. Holding other estimated coefficients unchanged, either lowering or increasing the value of $\Gamma$ would worsen the $p$-value. The lower and upper bounds of financiers' risk bearing capacities have been found, which are $\Gamma_{L}=0.05$ and $\Gamma_{U}=0.95$, respectively. Thus, international financial imperfections indeed have effects on the UK economy 17 .

\subsection{How Reliable is the Estimated Model?}

As the model users such as the policymaker, they might want to know how much they can trust this estimated model. To assess the chances of the test rejecting general parameter error we do a Monte Carlo experiment. We generate 10,000 samples from this model as the True model and then perturb all the parameters alternately by + or $-\mathrm{x} \%$ where we call $\mathrm{x}$ the 'degree of

\footnotetext{
${ }^{17}$ Many analyses, such as $\overline{\text { Meenagh et al. }}$ (2010), have been made with an Real Business Cycle open economy model of UK under uncovered interest parity and they have all passed the tests used in this paper. However, what this paper does is to investigate the case where there is a financial friction. Given UK experience the idea of a financial friction in foreign lending appears plausible.

The full UIP model and the financial friction model are non-nested: they are alternative ways of modelling foreign relationships. It is quite possible both can match the data. This might suggest that there is some more general model that nests them both; for example, it might be that sometimes there is UIP and sometimes there is friction. However, we do not investigate this here.
} 
Table 3: Rejection rates of Indirect Inference test for 3 variables (output, real interest rates and real exchange rates)

\begin{tabular}{llllllll}
\hline Falseness $(\%)$ & True & 1 & 3 & 5 & 7 & 10 & 15 \\
\hline Rejection Rate & 5.0 & 7.2 & 9.5 & 27.0 & 70.5 & 99.7 & 100 \\
\hline
\end{tabular}

falseness'. We can carry out our test on each False model and check how many of the 10,000 samples would reject it.

The Monte Carlo results are shown in Table 3 where it can be seen that once the model is $10 \%$ or more False rejection reaches $100 \%$. This implies we can be sure, since the model we have has not been rejected, that it must be within a bound of True to $10 \%$ False.

\section{Model Analysis}

\subsection{Impulse Response Analysis}

We start with two experiments designed to illustrate how the effects of shocks are magnified and distinct by the financial market imperfections, and how shocks arising in the financial sector itself influence the economy through currency risk-taking channel.

Figure 1 and Figure 2 show the response of the model economy to two disturbances: an external demand shock and a risk premium shock respectively. In each figure the red solid line shows the response of the estimated baseline model. The black dotted line gives the response of the model with nearly frictionless financial market $(\Gamma \approx 0) 18$.

A $10 \%$ temporary drop in foreign demand results in an excess supply of the domestic goods, which generates a current account deficit and a rise in net foreign debt. On the one hand, the global financial intermediary currency risk-taking mechanism produces a modest amplification of the depreciation in the real exchange rate in the estimated baseline model relative to the model

\footnotetext{
${ }^{18}$ The model with $\Gamma=0$ would introduce serious computational difficulties because the long-run levels of endogenous variables will depend on the behaviour of the non-stationary driving variables and "all available techniques are valid locally around a given stationary path" (Schmitt-Grohe and Uribe 2003, p.164). Here, I set $\Gamma=0.0001$ rather than $\Gamma=0$ for computational simplicity.
} 

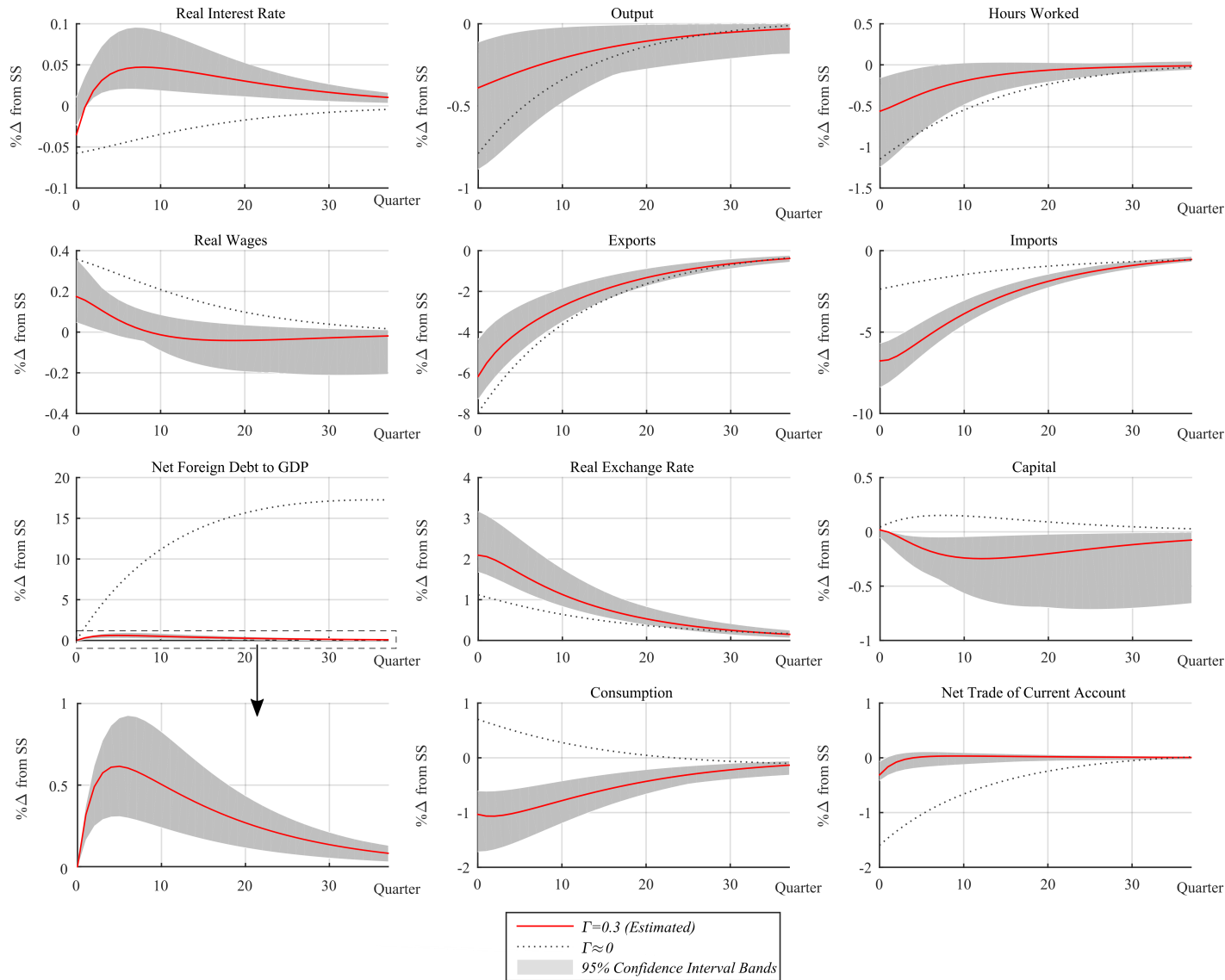

Figure 1: IRFs for a negative $10 \%$ external demand shock to the estimated baseline model and the model with nearly perfectly functioning financial market 

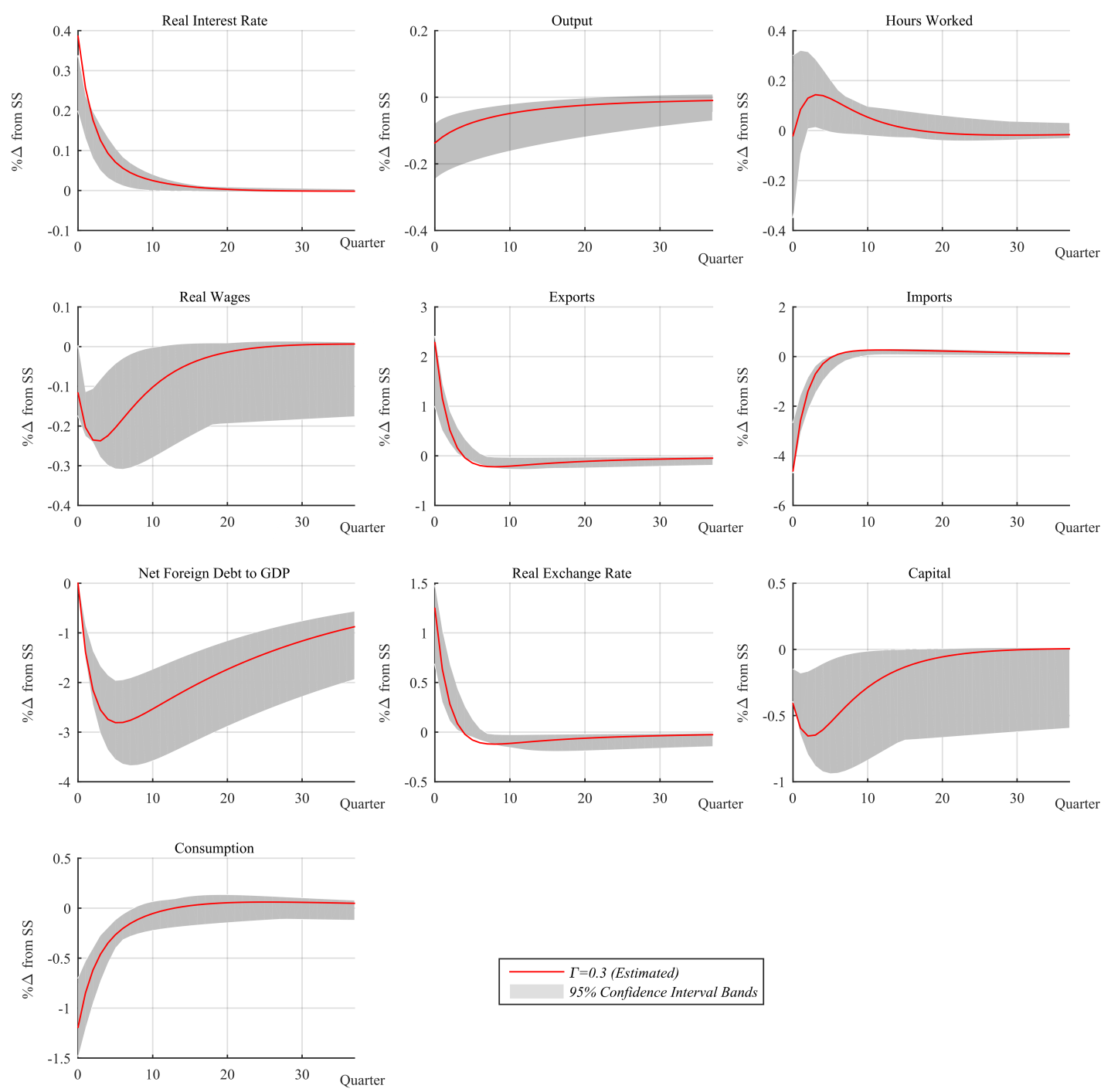

Figure 2: IRFs for a $1 \%$ global risk aversion shock to the estimated baseline model 
with nearly perfectly functioning financial market $(\Gamma \approx 0)$. The amplification is mainly the product of the rise in exchange rate risk premium due to global financiers' limited risk-bearing capacities. In the model without friction, of course, the premium is fixed at zero.

On the other hand, the financiers' limited commitment constraint leads to the opposite responses of domestic consumption and capital demand to external demand shock in the estimated baseline model, in contrast to those in the model with nearly perfectly functioning financial market. When the constraint binds, domestic households are not able to smooth out the impacts of the temporary export shock by running up foreign debts. This means, on effect, the domestic interest rate has to shoot up to drive down the domestic consumption. The increase in the cost of the capital reduces capital demand.

Global financial intermediaries act as shock absorbers; however, they are themselves the source of financial shocks that disturb the real economy. Here, we call them "global risk aversion shock". An unanticipated $1 \%$ global risk averse shock reduces financiers' risk bearing capacities. To incentivise global financiers to intermediate capital flows, the real exchange rate has to depreciate immediately and be expected to appreciate in the future through currency risk-taking channel. A tighter liquidity in international financial market pushes up the domestic interest rate, which induces a fall in domestic demand, including consumption, import and capital demand. In turn, output contracts. The labour market is also affected by the financial shock: real wage and hours worked decline initially as the shock hits the economy.

\subsection{A Stochastic Variance Decomposition of the Financial Disruption Episode}

Based on the estimated baseline model, we investigate what are the main driving forces of the sterling exchange rate during the episodes of financial disruptions by using a forecast error variance decomposition (or just variance decomposition for short) of the episode over 2006Q4 to 2016Q4, covering the global financial crisis and the Brexit vote.

Table 4 gives the variance decomposition of the sterling exchange rate, output, real interest rate and consumption. Shocks to financial forces account for more than $72 \%$ of the error variance 
of the sterling exchange rate during the period of financial disruptions. Furthermore, the bulk of the remainder comes from supply shocks, such as the productivity shock, the wage cost shock and the labour supply shock, which together contribute to 17 percent of the variation. The results of the variance decomposition of the exchange rate emphasises the crucial role of the currency risk-taking channel in explaining the variation of the sterling exchange rate in the imperfect financial market.

Intuitively, the UK holds a large stock of external liabilities and is reliant on the willingness of international financiers to keep buying UK assets. During a prolonged period of heightened uncertainty (like Brexit vote), international financial institutions balance sheet risks increase. Thus, they could either continue to be deterred from holding Sterling or demand more currency premium. Deterioration in investor appetite for UK assets-which could prompt more downward pressure on the exchange rate. Sterling, as an external debtor s currency, is vulnerable to shocks to financial forces.

Shocks to financial forces explain more than a quarter of the variations in consumption, since costs of borrowing from the rest of the world to maintain the standard of consumption surge when there is a financial disruption. In addition, movements in consumption are primarily driven by supply shocks that affect the intra-temporal equations and another two shocks that influence the intertemporal Euler equations, i.e. the consumer preference shock which has impacts on both the consumption and investment and the factor demand shock which affects the investment, in turn, the consumption.

Table 4 also illustrates that shocks to financial forces explain a minor fraction of the total variations in both the level of output and the interest rate, approximately $4 \%$, whereas supply shocks, especially the productivity shock, play significant parts in generating the movements of them.

Therefore there is a distinct role for shocks to financial forces in such episodes of the financial disruption, and those shocks have important effects on the economy in this model, particularly the variation of sterling exchange rates. 
Table 4: Variance Decomposition of the Reduced Form Shocks: 2006Q4-2016Q4

\begin{tabular}{lllll}
\hline Shocks & $\begin{array}{l}\text { Sterling Ex- } \\
\text { change Rate }\end{array}$ & Output & $\begin{array}{l}\text { Real Interest } \\
\text { Rate }\end{array}$ & Consumption \\
\hline Shocks to Financial Forces $^{\mathrm{b}}$ & 72.33 & 4.08 & 4.44 & 27.63 \\
Supply Shocks $^{\mathrm{c}}$ & 16.95 & 40.11 & 64.08 & 22.55 \\
Other Demand Shocks $^{\mathrm{d}}$ & 10.72 & 55.81 & 31.48 & 49.82 \\
\hline Total & 100 & 100 & 100 & 100 \\
\hline Notes: & & & &
\end{tabular}

a) The values in the table are in the percentage level.

b) The import demand shock and the export demand shock have impacts on the country's net foreign debt position, which in turn affect financier's balance sheet; while the global risk aversion shock has an influence on financiers risk bearing capacity. To emphasise the financiers risk-taking channel, these three shocks are classified as shocks to financial forces.

c) Supply shocks include the productivity shock, the wage cost shock, and the labour supply shock.

d) Other demand shocks include the consumer preference shock, the factor demand shock, the government demand shock, the foreign consumption shock and the foreign consumer preference shock.

\subsection{Historical Decomposition of the Financial Disruption Episode}

We then analyse what the estimated model says should happen in the economy over the same period of 2006Q4 to 2016Q4. In particular, we use the charts that follow for two main macro variables: sterling real exchange rate and output.

As can be seen in the top panel of Figure 3, the pound experienced a sharp depreciation as the global recession loomed at the end of 2008 , and shocks to financial forces made a major contribution to the surge in the sterling exchange rate. The unexpected decline in global financial institutions risk bearing capacity and the increase in their balance sheet risk could prompt more depreciation pressure on the exchange rate of an external net debtor such as the sterling exchange rate.

Sterling depreciated to record level against top trading partners after the Brexit referendum vote at the third quarter of 2016. The departure from the European Union imposed an uncertainty on the UK's future trade policy, fuelling fear and a lack of confidence. Not surprisingly, shocks to financial forces played a dominant role in the pound depreciation. The foreign demand of Sterling dropped due to the uncertainty of the UK's economy after the Brexit vote. Notice that 

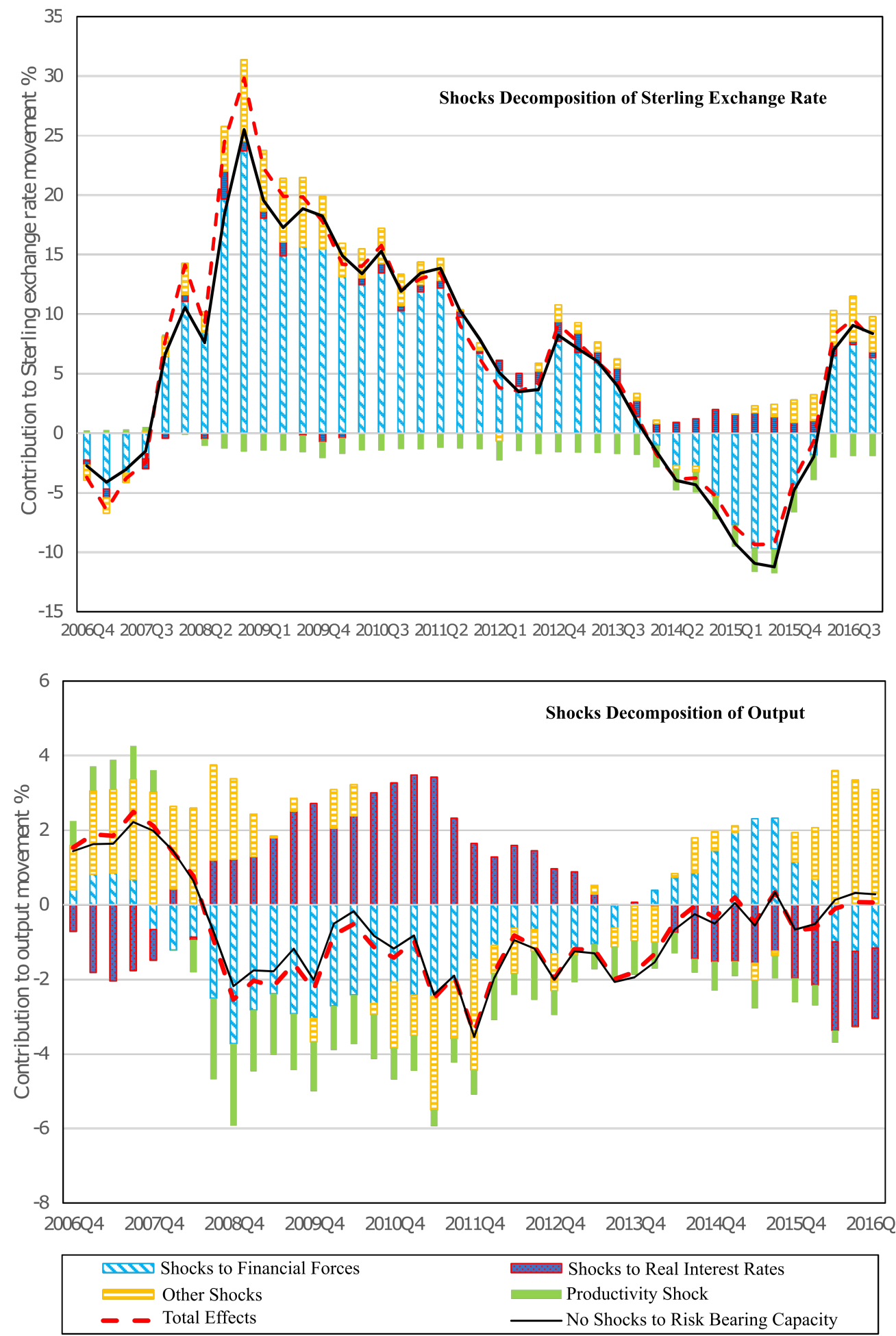

Figure 3: Shocks decomposition of sterling exchange rate and output 
the red dash line in Figure 3 describes the path for Sterling behaviour for the baseline model in which all the structural shocks are considered, and the solid black line outlines the path for the model where the global risk aversion shock is excluded. By comparing those two paths for Sterling, we can find that the shock to the willingness of financiers to absorb exchange rate risk can produce the exchange rate disconnect properties and enlarge the volatility of sterling during a financial disruption.

The bottom panel of Figure 3 shows how the estimated baseline model suggests the shocks drove output of the UK in the episode of financial disruptions. Britain entered a recession in the third quarter of 2008. In particular, productivity shocks play a largely dampening role on output, and shocks to financial forces are by far the most crucial component of the negative shocks to the output. After the collapse of Lehman Brothers, the major central banks in the world stepped in the financial market. The base interest rates were globally cut to historically low levels, aiming to stimulate the economy. And the interest rates on foreign bonds dropped, which lowered the cost of foreign borrowing. Thus, shocks to interest rates made positive contributions to the domestic output over 2009 to 2011.

Although shocks to financial forces and the interest rate differential channels imposed downward pressure on output, Britain's economy continued growing in the three months after the EU referendum because of the strong fundamentals of the UK economy.

\section{Implications of the Model for Optimal Policy Rules}

As a policymaker, you might want to know what would happen when a financial confidence shock and fiscal policy (we interpret it here as a government spending shock) hit the economy. Three key macroeconomic variables - output, real interest rate and real exchange rate have been chosen to analyse.

The upper panel of Figure 4 shows the effects of a decline in financial confidence in both the models with financial imperfections and perfections. In the model with financial imperfections, 
the effect is to tighten credit conditions in the global financial market and, in turn, push up the domestic real interest rate, which contracts the domestic aggregate demand. This drives down output immediately. Financiers require currency risk premiums to facilitate capital flows, thus the real exchange rate depreciates and is expected to appreciate. The lower panel of Figure 4
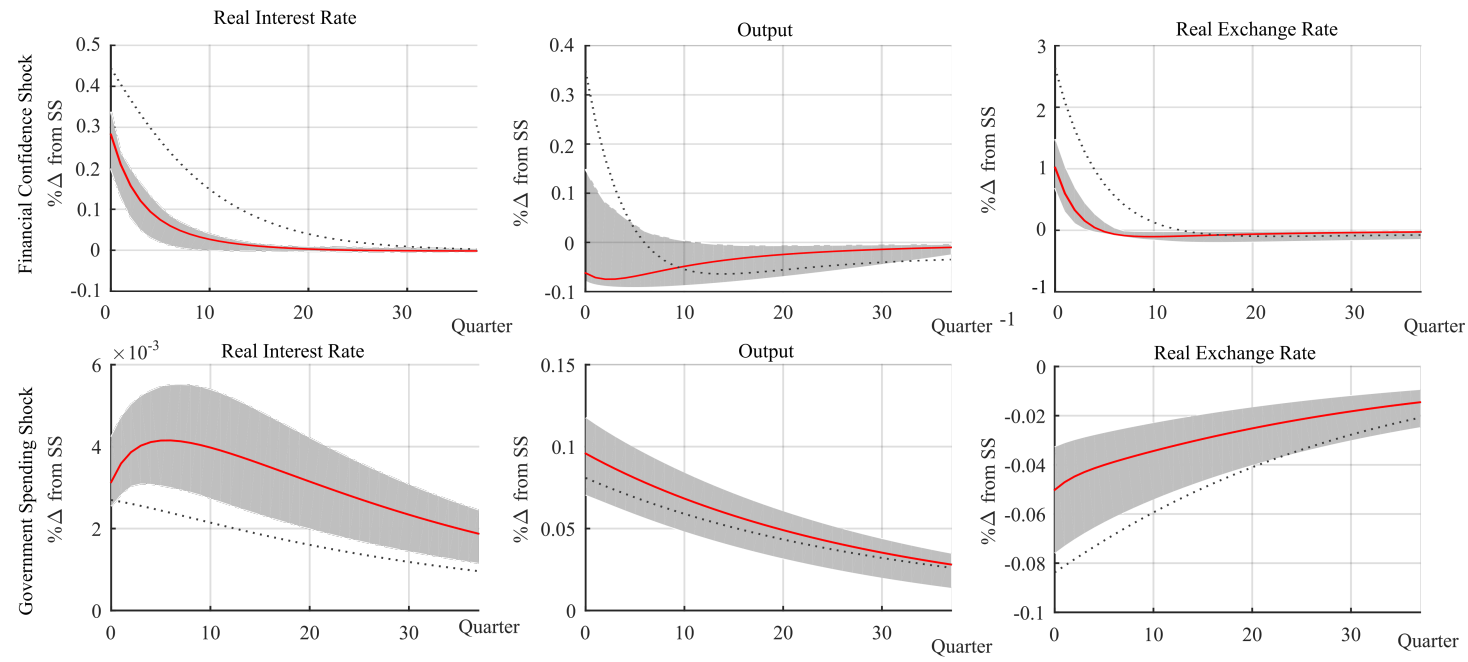

$$
\begin{aligned}
& \hline \ldots \ldots . . \Gamma=0.3 \text { (Estimated) } \\
&=0 \\
& 95 \% \text { Confidence Interval Bands }
\end{aligned}
$$

Figure 4: Responses to $1 \%$ financial confidence shock and government spending shock in the estimated baseline model and the model with the perfect functioning international financial market

exhibits the impacts of a rise in government spending in both the estimated baseline model and the model with the perfect functioning international financial market. The government spending shock is more effective on output in the imperfect financial model than that in the perfect financial model. Thus, we argue that fiscal policy might hold the key to responding to crisis conditions.

We now focus on the estimated baseline model with financial imperfections and consider the welfare losses from responses to economic cycles through a macroprudential policy rule, a fiscal rule and a combination of those two rules, and compute the optimal degree of reaction. We take the variance of output and the variances of consumption and labour supply as the objectives. For simplicity, we assume the distortions created by macroprudential policy would be offset by 
lump-sum transfer 19 .

We consider a simple specification where the authority could affect the interest rate on domestic bonds applicable to the international asset market in period $t$ according to the macroprudential policy rule

$$
R P_{t}=v\left(\frac{\widetilde{D_{t}}}{\widetilde{D_{t-1}}}-1\right)
$$

where $R P_{t}$ is the regulation premium, which is defined as an increasing function of the net foreign debt growth in the economy. It implies that the growth of net foreign debts or capital flows has been chosen as the policy objective. $v$ is the adjusted coefficient.

In the presence of the macroprudential regulation, the domestic households' borrowing costs have been affected by the regulation premium,

$$
r_{t}=r_{t}^{f}+\ln Q_{t+1}-\ln Q_{t}+\Gamma \widetilde{d_{t+1}}+R P_{t} 20
$$

When the net foreign debt grows, macroprudential measures raise the cost of financial intermediation, these costs are then passed onto domestic borrowers in the form of higher borrowing rate. This, in turn, reduces the capital inflow during boom periods, driving down the demand for domestic currency (real exchange rate depreciation) and lowering trade deficits 21

Since the government authority could manipulate his budget to exert influence on aggregate demand, conventional fiscal policies can be utilised to smooth out the extreme swings of the business cycle and stabilise the whole economy. Here, we model a countercyclical fiscal policy in terms of a simple and implementable rule in which the government adjusts its spending by

\footnotetext{
${ }^{19}$ The macroprudential policy creates a wedge between the flexible price cost of capital and the prudential cost. Since the distortion is negligible and difficult to measure, we assume the cost of capital caused by the prudential policy could be offset by paying subsidy to firms.

${ }^{20}$ This equation is the log-linearization of the determination of real exchange rate (Equation 20 ) plus the regulation premium. And $\widetilde{d_{t+1}}$ is a ratio of home countrys net foreign debt to real GDP at date t, i.e. $\widetilde{d_{t+1}}=\frac{D_{t+1}}{Y_{t+1}}$.

${ }^{21}$ The aim of the paper is to emphasise the importance of the channel of financial intermediaries. Thus, we follow Quint and Rabanal (2014) and Ozkan and Unsal (2014) to focus on a generic case where macroprudential measures raise the cost of financial intermediation. It should be noted that any effects of nominal shocks to demand are included in the IS curve error term.
} 
Table 5: Stability Under Different Policy Rules

\begin{tabular}{lllll}
\hline & Baseline & $\begin{array}{l}\text { Macro- } \\
\text { prudential } \\
\text { Policy }\end{array}$ & Fiscal Policy $^{\mathrm{d}}$ & $\begin{array}{l}\text { Macro- } \\
\text { prudential } \\
\text { Policy+Fiscal } \\
\text { Policy }\end{array}$ \\
\hline $\begin{array}{llll}\text { Frequency of crisis } \\
\text { Exp Welfare Cost (1) }\end{array}$ & 20.93 & 19.21 & 14.99 & 13.64 \\
Variance(cons) & $-30 \%$ & $-16 \%$ & $-46 \%$ \\
Variance(hours) & $-33 \%$ & $-11 \%$ & $-42 \%$ \\
Exp Welfare Cost (2) & $0 \%$ & $-60 \%$ & $-80 \%$ \\
Variance(output) & & $-19 \%$ & $-25 \%$ & $-50 \%$ \\
\hline
\end{tabular}

Notes: $\quad$ a. Expected crisis per 1000 years.

c. Optimal coefficient of policy rule $v=0.001$.

b. Equal weights for each variance.

d. Optimal coefficient of policy rule $\xi=2.5$.

choosing the size of $\xi$ in response to the output gap,

$$
\ln G_{t}=\rho_{G} \ln G_{t-1}-\xi\left(\ln Y_{t}-\ln \bar{Y}\right)+\eta_{G, t}
$$

where $\ln Y$ denotes the long-term trend in output. $\xi$ is the coefficient of output gap in the government fiscal tool.

In an overheated expansion with a positive output gap, a contractionary fiscal policy reduces government spending; while an expansionary policy increases government spending to stimulate the economy during a recession with a negative output gap.

The coefficients of policy rules $\{v, \xi\}$ have been derived optimally by computing the values that minimize the total welfare cost of economic agents under all the structural shocks. Table 5 presents a comparative analysis of alternative policies in terms of the frequency of crisis and two groups of variances. Expected welfare costs are expressed in percentage changes in terms of the variances of consumption, labour supply and output relative to the baseline economy. A smaller welfare loss indicates that the policy is more desirable from a welfare point of view.

A thousand bootstrapped simulations have been run for each policy rule. Clearly, the three policy rules inject stabilising action when the economy collapses or surges. We observe that the 
welfare loss decreases by around 46 percent of variances of consumption and labour supply and by about $50 \%$ of the variance of output under a combination of macroprudential policy rule and fiscal policy rule. In terms of the consumer's utility, the reduction in welfare loss from using the macroprudential instrument is significant compared to the fiscal policy. In particular, the macroprudential rule plays a significant role in smoothing out consumption and decreases the volatility of consumption by 33 percent. However, the economy with the fiscal policy rule experiences much smaller fluctuation in output than the economy with the macroprudential instrument.

Moreover, we investigate economic stability implied by the model with each policy rule in terms of frequency of crisis. Here a 'crisis' is defined as a severe interruption in output growth for at least three years. We bootstrap the model with each policy rule and the full sample of implied shocks to see whether implementing policy rules could help to reduce the frequency of crisis. The result shows that the combination of fiscal and macroprudential rules offers a big rise in the stability by reducing the number of crises per 1000 years to 13.64 from the baseline 20.93. In other words, the frequency comes down to one episode every 73 years from the baseline 48 years under the combination of these two policy rules.

\section{Concluding Remarks}

In this paper, we provide a tractable general equilibrium framework for the determination of the sterling exchange rate in imperfect financial markets. The models implied behaviour fits the UK data behaviour over the period of 1975 and 2016 by using Indirect Inference method. The study documents a new finding that financial market disturbances are the main driving forces behind the large and sudden depreciation of the sterling exchange rate in the aftermath of the collapse of Lehman Brothers and the Brexit vote.

The framework remains stylised and can be further developed. It could be for example that incorporating various nominal rigidities and heterogenous agents, which would be useful for monetary policy analysis. However, our concern here has been a preliminary one: to establish 
the basic ability of the flexprice real business cycle model with financial market imperfections to provide explanatory power. The model allows us to analytically flesh out the crucial forces in the financial markets without carrying around a burdensome real structure.

Overall, we provide empirical support for the importance of financial forces, for example financiers risk bearing capacities, in explaining the sterling exchange rate dynamics. 


\section{Appendix A: Data Description}

We use data over the period 1975Q1-2016Q4 on eleven UK macroeconomic variables: output, consumption, capital stock, export, import, total hours worked, real wages, real interest rates, real exchange rates, net foreign debt to GDP ratio, government spending. Two variables for the rest of the world: world consumption and foreign real interest rates. We convert all real variables to a per capita basis by dividing by an working-age population index. All variables are expressed in constant prices and seasonally adjusted, unless specified otherwise. Most of variables are in natural logs, except where variables have already been expressed in percentages, such as net foreign debt to output and interest rates.

There are some reasons why we use unfiltered data in this paper. First of all, the filters available do not seem appropriate and precise to decompose a non-stationary time series arbitrarily into a 'long run potential trend' component and swings around it since some transitional periods following a shock may be reasonably long in the model, and long cyclical swings might be mistakenly treated as a trend and removed by filters. Secondly, we would like to keep the features of non-stationarity and do not remove the stochastic trend. One of the important interests in this study is about how the stochastic trend behaviours, which arise from the unit root processes of technology shock, transfer through the entire model. Stationarising the data may potentially distort some of the interactions of interests and the dynamic properties of the model in ways that are not easy to uncover.

The majority of UK data are sourced from the UK Office of National Statistics (ONS). Others from Bank of England (BoE), Federal Reserve Bank of St. Louis, Bank for International Settlements (BIS), International Monetary Fund (IMF).

This Appendix includes all definitions, sources of data, symbol keys and the detail of transformations of some data series used in the paper. 


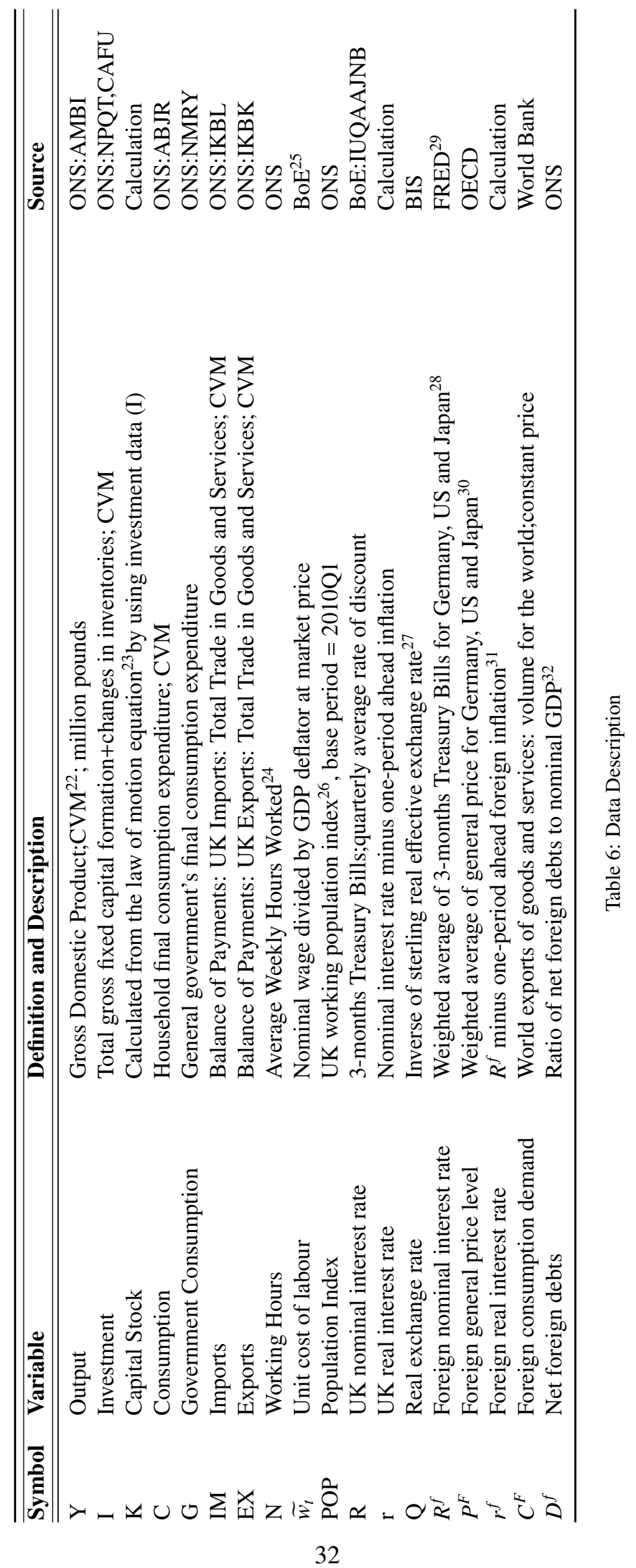


Notes to Table 6:

15. CVM represents chained volume measures.

16. Law of motion equation is $K_{t}=(1-\delta) * K_{t-1}+I_{t}$. Here is the process of calculating capital stock,

Step 1: start with the K/Y ratio (capital output ratio=2.69);

Step 2: For a given year, I use initial output to calculate capital in first period $\frac{K}{Y} * Y_{1975 Q 1}=$ $K_{1975 Q 1}$ (initial value);

Step 3: Generating capital based on law of motion equation, $K_{1975 Q 2}=(1-\delta) * K_{1975 Q 1}+I_{1975 Q 2}$.

17. Total employment (ONS code: MGRZ; units: thousands ); Total actual weekly hours worked (ONS code: YBUS, units:millions); Take the number of MGRZ, normalized so that its 2010Q1 value is 1 , called it total employment index(MGRZ index); $N=\frac{Y B U S}{M G R Z} * M G R Z$ index.

18. The real weekly wage data series is collected from "A millennium of macroeconomic data for the UK”, Version 3, Bank of England.

Here is the website: http://www.bankofengland.co.uk/research/Pages/datasets/default.aspx.

19. Working population is the sum of total claimant count (ONS code: BCJD) and UK workforce jobs (ONS code: DYDC); take the number of working population, normalized so that its 2010Q1 value is 1 , called it working population index.

20. Based on the bilateral trade with the UK, the sterling to euro, the sterling to dollar, and the sterling to Japanese yen bilateral exchange rates have been assigned majority of the weights in calculating sterling real effective exchange rate indices.

Please find the detail in http://www.bis.org/statistics/eer.htm

21. According to the weights in sterling real effective exchange rate indices, the weighted average of nominal interest rate in Germany(0.62), US(0.23), Japan(0.15);Germany is a proxy for European Union.

22. FRED denotes Federal Reserve Bank of St. Louis; OECD stands for Organisation for Economic Co-operation and Development, data website https://data.oecd.org/

23. The weights assigned for countries in $P^{F}$ is the same as the weights in $R^{f}$.

24.One period ahead inflation (year-on-year change in $P^{F}$ ) based on the formula-inflationrate = $\frac{C P I_{t}-C P I_{t-1}}{C P I_{t-1}}$.

25. Nominal net foreign debt is accumulated current account deficits (millions of pounds), taking the Balance of Payments international investment position as a starting point (ONS code: HBQC at 1974). I converted annual data series to quarterly by quadratic-match-sum. 


\section{Appendix B: The Log-linearised Model}

The competitive equilibrium of the model can be described by a system of non-linear stochastic difference equations, which can be expressed in an implicit form

$$
f\left(E_{t} y_{t+1}, y_{t}, \varepsilon_{t}, \eta_{t}\right)=0
$$

where $f($.$) is an k \times 1$ vector value function. $y_{t}$ is a set of variables, $E_{t} y_{t+1}$ is the expectation of $y_{t+1}$ formed by the model's decision makers conditional on information available up to and including period $t$,

$$
E_{t} y_{t+1}=E\left(y_{t+1} \mid y_{t}, y_{t-1}, y_{0}\right) .
$$

Log-linearised representations of structural models are expressed as

$r_{t}=\ln \frac{1}{\beta}+\gamma_{C}\left(\ln E_{t} C_{t+1}-\ln C_{t}\right)+\ln \varepsilon_{t}^{r}$ (Euler Equation $)$

$\ln Y_{t}=\alpha \ln N_{t}+(1-\alpha) \ln K_{t}+\ln A_{t}($ Production Equation $)$

$\ln N_{t}=\ln \alpha+\ln Y_{t}-\ln \widetilde{w}_{t}+\ln \varepsilon_{t}^{N^{d}}($ Labour Demand Equation)

$\ln K_{t}=\zeta_{1} \ln K_{t-1}+\zeta_{2} E_{t} \ln K_{t+1}+\zeta_{3} \ln Y_{t}-\zeta_{4} r_{t-1}+\ln \varepsilon_{t}^{K}$ (Capital Demand Equation)

$\ln C_{t}=\frac{\bar{Y}}{\bar{C}} \ln Y_{t}-\frac{\bar{K}}{\bar{C}} E_{t} \ln K_{t+1}+\frac{(1-\delta) \bar{K}}{\bar{C}} \ln K_{t}-\frac{\bar{G}}{\bar{C}} \ln G_{t}-\frac{\overline{E X}}{\bar{C}} \ln E X_{t}+\frac{\overline{I M}}{\bar{C}} \ln I M_{t}($ Goods Market Condition $)$

$\ln \widetilde{w}_{t}=\gamma_{N} \ln N_{t}+\frac{1-\omega}{\omega} \ln Q_{t}+\gamma_{C} \ln C_{t}+\ln \varepsilon_{t}^{N}$ (Labour Supply Equation)

$\ln E X_{t}=\ln \left(1-\omega^{F}\right)+\theta^{F} \ln Q_{t}+\ln C_{t}^{F}+\ln \varepsilon_{t}^{E X}$ (Export Equation)

$\ln I M_{t}=\ln (1-\omega)+\ln C_{t}-\theta \ln Q_{t}+\ln \varepsilon_{t}^{I M}$ (Import Equation)

$\widetilde{d_{t+1}}=\left(1+\widetilde{r_{t-1}}\right) \widetilde{d}_{t}+\frac{\overline{I M}}{\bar{Y}}\left(\ln I M_{t}+\ln Q_{t}\right)-\frac{\overline{E X}}{\bar{Y}} \ln E X_{t}($ Evolution of Net Foreign Debts $)$

$\ln Q_{t}=\ln E_{t} Q_{t+1}+r_{t}^{f}-r_{t}+\Gamma \widetilde{d_{t+1}}+\ln \varepsilon_{t}^{\Gamma}$ (Financiers' Demand for Sterling Bonds)

$\ln G_{t}=\rho_{G} \ln G_{t-1}+\eta_{G, t}($ Government Spending Equation $)$

$\ln C_{t}{ }^{F}=\rho_{C^{F}} \ln C_{t-1}^{F}+\eta_{C^{F}, t}($ Rest of the World Demand Equation $)$

$r_{t}^{f}=\rho_{r^{f}} r_{t-1}^{f}+\eta_{r^{f}, t}($ Rest of the World Real Interest Rate Equation). 


\section{Appendix C: The Method of Indirect Inference}

Indirect Inference was first introduced into the econometrics literature by Smith (1993), and extended as a general simulation-based method for estimation of structural models by Gourieroux et al. (1993). Moreover, Indirect Inference can be used in a structural macroeconomics model evaluation, which was proposed in Minford et al. (2009) and refined by Le et al. (2011) who used Monte Carlo experiments to evaluate the power of the Indirect Inference test.

We use Indirect Inference rather than the recent widely-used Bayesian method to estimate our model here, since we aim to test the model against the data. The Bayesian method cannot judge models in the classical hypothesis testing sense, they treat all models as false and evaluate each model's probability of being right instead. It is not precisely where the line is drawn between failure and success for the model. Moreover, a criticism of the Bayesian method is the choice of the priors that is subjective. Any model ranking or probability assessment we made under the Bayesian approach would be biased if priors are incorrect. As the first empirical study in the literature to estimate financiers' risk bearing capacity $(\Gamma)$ there is no prior information on this parameter and the Bayesian method is not applied here.

By contrast, Indirect Inference provides a classical statistical inferential framework for judging whether a model with a particular set of parameters could have generated the behaviour found in a set of actual data. The Indirect Inference test is to compare the performance of the auxiliary model based on the actual data with its performance based on the data simulated from the macroeconomic model. The auxiliary model is employed to form a criterion function in the indirect inference tes ${ }^{33}$. This criterion does not need to be an accurate description of the data generating process. Common choices of this criterion are the scores, impulse response function, or actual coefficients. Here we choose the auxiliary model parameter estimates (or functions of these) as the descriptors of the data. The structural model is then simulated ${ }^{34}$. We use a Wald statistic depending on the distance between $\beta^{a}$, the estimates of data descriptors based on actual data, and $\overline{\beta^{s}\left(\widehat{\theta_{0}}\right)}$, the mean of their distribution based on multiple independent sets of the

\footnotetext{
${ }^{33}$ The auxiliary model is independent of the theoretical model and the performance of the theory is evaluated indirectly against it. It "serves as a window through which to view both the observed data and the simulated data generated by the economic model: it selects aspects of the data upon which to focus the analysis" (Durlauf and Blume. 2008).

${ }^{34}$ The structural residuals of each equation are backed out from the observed data and the DSGE model. The resulting structural residuals are treated as the error process in the model and together with exogenous variable processes, process the shocks perturbing the model. Instead of assuming shocks follow asymptotic distributions, the shocks are bootstrapped by time vector to preserve any correlations between them.
} 
simulated data, which is given by

$$
W S=\left(\beta^{a}-\overline{\beta^{s}\left(\widehat{\theta_{0}}\right)}\right)^{\prime} \Omega^{-1}\left(\beta^{a}-\overline{\beta^{s}\left(\widehat{\theta_{0}}\right)}\right),
$$

where $\widehat{\theta_{0}}$ is the vector of parameters of the DSGE model on the null hypothesis that it is true 35 $\Omega=\operatorname{cov}\left(\beta^{i}\left(\widehat{\theta_{0}}\right)-\overline{\beta^{s}\left(\widehat{\theta_{0}}\right)}\right)=\frac{1}{s} \sum_{i=1}^{s}\left(\beta^{i}\left(\widehat{\theta_{0}}\right)-\overline{\beta^{s}\left(\widehat{\theta_{0}}\right)}\right)\left(\beta^{i}\left(\widehat{\theta_{0}}\right)-\overline{\left.\beta^{s}\left(\widehat{\theta_{0}}\right)\right)^{\prime}}\right.$ is the variance-covariance matrix of the distribution of simulated estimates $\beta^{i}$. Thus, if the model proposed in Section 2 is correct, the estimates of data descriptors based on the actual data will lie in some confidence interval implied by their distribution derived from multiple independent sets of the simulated data. To estimate the structural model we use a Simulated Annealing algorithm in which the search takes a place over a wide range around the calibrated values to find the minimum-value Wald statistic for the model. This gives the best fit of parameters that produce the simulations that are statistically the closest to actual data.

In practice, the solution to a log-linearised DSGE model takes the form of a restricted vector autoregressive and moving average (VARMA), or approximately, a vector autoregressive (VAR ${ }^{36}$ Following Le et al. (2016), we use a VECM as the auxiliary model for non-stationary data, which is then re-expressed as a cointegrated VAR with exogenous variables (VARX(1)) for our three main macroeconomic variables of interest (real interest rate, output and real exchange rate) including a time trend, and net foreign debt to GDP ratio and productivity residual as non-stationary exogenous variables. These exogenous terms have the impact of achieving cointegration. We examine the structural model's ability to encompass the dynamics, volatility and cointegrating relations observed in the data. To this end, we use the VARX(1) coefficients and the VARX(1) error variances as our descriptors of the data and then compute a Wald statistic from these.

\section{The auxiliary model}

We choose a cointegrated VARX(1) as the auxiliary model,

$$
y_{t}=\text { intercept }+A y_{t-1}+(I-A) \Pi x_{t-1}+f t+\varsigma_{t}
$$

where the error term $\varsigma_{t}$ contains the suppressed lagged difference regressors, $f t$ is included to capture a deterministic linear trend that affects both the endogenous and exogenous variables, $x_{t-1}$ contains stochastic trend which must be present to control for the effect of past shocks of

\footnotetext{
${ }^{35} \overline{\beta^{s}\left(\widehat{\theta_{0}}\right)}=E\left(\beta^{i}\left(\widehat{\theta_{0}}\right)\right)=\frac{1}{s} \sum_{i=1}^{s} \beta^{i}\left(\widehat{\theta_{0}}\right)$ denotes the sample average of estimates of the coefficients in auxiliary model based on $s$ sets of simulated data from the macroeconomic model, taking $\widehat{\theta_{0}}$ as given.

${ }^{36}$ Gourieroux et al. (1993) show that a correct inference can be based on an 'incorrectly' specified auxiliary model. When the auxiliary model is correctly specified, the indirect inference is equivalent to maximum likelihood.
} 
the model on the long-run path of endogenous and exogenous variables.

The small open economy DSGE model with financial market imperfections derived in Section 2 serves as an internally consistent backdrop for us to examine, with statistical formality, the causally identified theory that financial force drives the behaviour of exchange rates. In this case, the focus is on the financial friction hypothesis and on the behaviour of real exchange rate, domestic interest rate, and output conditional on net foreign debt to GDP ratio and productivity. Thus, we include $Q_{t}, r_{t}, Y_{t}$ as endogenous variables and $\widetilde{d_{t-1}}$ and $A_{t-1}$ as exogenous variables in the auxiliary model to evaluate the structural model on this joint criterion.

Recall that the VARX(1) in 32 is the approximation to the reduced form of the structured model. Here, the VARX(1) has been specified in the form of [33), which serves as the unrestricted auxiliary model used throughout the test and estimation in the empirical work, being a parsimonious description of some key features of the DSGE model with currency premium derived in Section 2.

$$
\left[\begin{array}{l}
Q_{t} \\
r_{t} \\
Y_{t}
\end{array}\right]=\left[\begin{array}{lll}
\beta_{11} & \beta_{12} & \beta_{13} \\
\beta_{21} & \beta_{22} & \beta_{23} \\
\beta_{31} & \beta_{32} & \beta_{33}
\end{array}\right]\left[\begin{array}{c}
Q_{t-1} \\
r_{t-1} \\
Y_{t-1}
\end{array}\right]+\left[\begin{array}{llll}
\beta_{14} & \beta_{15} & \beta_{16} & \beta_{17} \\
\beta_{24} & \beta_{25} & \beta_{26} & \beta_{27} \\
\beta_{34} & \beta_{35} & \beta_{36} & \beta_{37}
\end{array}\right]\left[\begin{array}{c}
\widetilde{d_{t-1}} \\
A_{t-1} \\
t \\
\text { const }
\end{array}\right]+\left[\begin{array}{c}
\varsigma_{1} \\
\varsigma_{2} \\
\varsigma_{3}
\end{array}\right]
$$

The coefficient vector $\beta^{s}$ in Equation 31 used to construct the Direct Wald statistic includes OLS estimates of $\beta_{11}, \beta_{12}, \beta_{13}, \beta_{14}, \beta_{21}, \beta_{22}, \beta_{23}, \beta_{24}, \beta_{31}, \beta_{32}, \beta_{33}, \beta_{34}$ and the variances of the fitted stationary residuals $\varsigma_{1}, \varsigma_{2}$ and $\varsigma_{3}$ based on each set of simulated data; the same coefficients make up $\beta^{a}$ estimated on the observed data. The coefficients represent the dynamic properties found in the model and data, and the three variances of the residuals measure the volatility properties.

Net foreign debt, $\widetilde{d_{t-1}}$ is included as an exogenous variable in the auxiliary model to capture the effect of net foreign debt on the behaviour of real exchange rate. In addition, productivity is measured by the Solow residual, which is backed out from the calibrated Cobb-Douglas production function on the assumption of constant returns to scale and fixed input shares. $A_{t-1}$ is a key non-stationary exogenous variable and is included in the VARX to provide cointegration, since its stochastic movements have impacts on the long run solution path of the endogenous variables. Moreover, the trend term, $t$, in the 33 captures the deterministic trend in the observed data and in the simulations.

We ask whether the model-implied OLS-estimated-VARX would generate the same OLSestimated -VARX as the observed data. More specifically, this is a test of whether the DSGE model can replicate the data features of real exchange rate, real interest rate and output jointly, in terms of their dynamics as well as their variance and covariance. 


\section{Appendix D: Model Derivation}

D.1 The Lagrangian for composite utility index maximization problem is

$$
\mathcal{L}_{t}=\left[\omega^{\frac{1}{\theta}}\left(C_{t}^{d}\right)^{\frac{\theta-1}{\theta}}+(1-\omega)^{\frac{1}{\theta}}\left(\varepsilon_{t}^{I M}\right)^{\frac{1}{\theta}}\left(C_{t}^{f}\right)^{\frac{\theta-1}{\theta}}\right]^{\frac{\theta}{\theta-1}}+\Lambda_{t}\left(C_{t}-p_{t}^{d} C_{t}^{d}-Q_{t} C_{t}^{f}\right)
$$

and the first order conditions for $C_{t}^{d}$ and $C_{t}^{f}$ are ${ }^{37}$

$$
\begin{gathered}
\frac{\partial \mathcal{L}_{t}}{\partial C_{t}^{d}}=\frac{\theta}{\theta-1}\left(\widetilde{C}_{t}\right)^{\frac{1}{\theta}}(\omega)^{\frac{1}{\theta}} \frac{\theta-1}{\theta}\left(C_{t}^{d}\right)^{\frac{-1}{\theta}}-\Lambda_{t} p_{t}^{d}=0 \\
\frac{\partial \mathcal{L}_{t}}{\partial C_{t}^{f}}=\frac{\theta}{\theta-1}\left(\widetilde{C}_{t}\right)^{\frac{1}{\theta}}(1-\omega)^{\frac{1}{\theta}} \frac{\theta-1}{\theta}\left(\varepsilon_{t}^{I M}\right)^{\frac{1}{\theta}}\left(C_{t}^{f}\right)^{\frac{-1}{\theta}}-\Lambda_{t} Q_{t}=0 .
\end{gathered}
$$

At the maximum, $\widetilde{C}_{t}=C_{t}, \frac{\partial \mathcal{L}_{t}}{\partial \widetilde{C}_{t}}=\Lambda_{t}, \frac{\partial \mathcal{L}_{t}}{\partial C_{t}}=1$, hence it follows that $\Lambda_{t}=1$ when the constraint binds, implying that the change in the utility index is unity due to a unit increase in consumption.

Hence, the domestic demand for home goods is given by optimality condition (35)

$$
C_{t}^{d}=\omega\left(p_{t}^{d}\right)^{-\theta} C_{t},
$$

and the domestic demand for foreign produced goods (import equation) is given by optimality condition 36), $C_{t}^{f}=I M_{t}=(1-\omega) \varepsilon_{t}^{I M}\left(Q_{t}\right)^{-\theta} C_{t}$.

D.2 The Lagrangian associated with household's maximization problem in period 0 is given by

$$
\begin{aligned}
L_{0}= & E_{0} \sum_{t=0}^{\infty} \beta^{t} E_{t}\left\{\omega_{0} \varepsilon_{t}^{r} \frac{C_{t}^{1-\gamma_{C}}}{1-\gamma_{C}}-\left(1-\omega_{0}\right) \varepsilon_{t}^{N} \frac{N_{t}^{1+\gamma_{N}}}{1+\gamma_{N}}\right. \\
& \left.+\lambda_{t}\left[w_{t} N_{t}+\Pi_{t}+D_{t+1}+\widetilde{D_{t+1}}-C_{t}-D_{t}\left(1+r_{t-1}\right)-\widetilde{D_{t}}\left(1+\widetilde{r_{t-1}}\right)-T_{t}\right]\right\},
\end{aligned}
$$

where $\beta^{t} \lambda_{t}$ denotes the Lagrange multiplier associated with the sequential budget constraint 77 . The first-order conditions corresponding to $C_{t}, N_{t}, D_{t+1}$, and $\widetilde{D_{t+1}}$, respectively, are

$$
\omega_{0} \varepsilon_{t}^{r} C_{t}^{-\gamma_{C}}-\lambda_{t}=0
$$

\footnotetext{
${ }^{37}$ Using the substitution

$$
\left[\omega^{\frac{1}{\theta}}\left(C_{t}^{d}\right)^{\frac{\theta-1}{\theta}}+(1-\omega)^{\frac{1}{\theta}}\left(\varepsilon_{t}^{I M}\right)^{\frac{1}{\theta}}\left(C_{t}^{f}\right)^{\frac{\theta-1}{\theta}}\right]^{\frac{\theta}{\theta-1}-1}=\left\{\left[\omega^{\frac{1}{\theta}}\left(C_{t}^{d}\right)^{\frac{\theta-1}{\theta}}+(1-\omega)^{\frac{1}{\theta}}\left(\varepsilon_{t}^{I M}\right)^{\frac{1}{\theta}}\left(C_{t}^{f}\right)^{\frac{\theta-1}{\theta}}\right]^{\frac{\theta}{\theta-1}}\right\}^{\frac{1}{\theta}}=\left(\widetilde{C}_{t}\right)^{\frac{1}{\theta}} .
$$
}




$$
\begin{aligned}
& -\left(1-\omega_{0}\right) \varepsilon_{t}^{N} N_{t}^{\gamma_{N}}+\lambda_{t} w_{t}=0 \\
& \beta^{t} \lambda_{t}-E_{t} \beta^{t+1} \lambda_{t+1}\left(1+r_{t}\right)=0 \\
& \beta^{t} \lambda_{t}-E_{t} \beta^{t+1} \lambda_{t+1}\left(1+\widetilde{r}_{t}\right)=0
\end{aligned}
$$

Household optimization implies that the constraints (8) and (9) hold with equality. The Euler Equation could be obtained by combining optimality conditions (39) and 41], describing intertemporal substitution in consumption

$$
\frac{U_{C}\left(C_{t}, N_{t}\right)}{1+r_{t}}=\beta E_{t} U_{C}\left(C_{t+1}, N_{t+1}\right) .
$$

It states that the price of an extra unit of utility from consumption today is $\frac{1}{\left(1+r_{t}\right)}$ in terms of tomorrow's expected marginal utility of consumption discounted by time preference. Dividing optimality condition (40) by optimality condition (39) to eliminate $\lambda_{t}$. This yields the intratemporal condition,

$$
-\frac{U_{N}\left(C_{t}, N_{t}\right)}{U_{C}\left(C_{t}, N_{t}\right)}=w_{t}
$$

This equates the marginal rate of substitution between leisure and consumption to their price ratio, the real wage. The left-hand side of expression (44) is the household's labour supply schedule, which is increasing in hours worked, holding the level of consumption constant 38 .

The optimality condition (41) for $D_{t+1}$ yields

$$
\frac{1}{1+r_{t}}=\beta \frac{\lambda_{t+1}}{\lambda_{t}}
$$

Combing Equation 45 with the optimality condition 42 for $\widetilde{D_{t+1}}$ to eliminate $\beta \frac{\lambda_{t+1}}{\lambda_{t}}$ yields a no-arbitrage condition,

$$
r_{t}=\widetilde{r}_{t}
$$

The intuition of this equality is that country residents can borrow and lend abroad at the critical rate required by foreign financiers.

\footnotetext{
${ }^{38} \mathrm{~A}$ sufficient condition for $-\frac{U_{N}\left(C_{t}, N_{t}\right)}{U_{C}\left(C_{t}, N_{t}\right)}$ to be increasing in $N_{t}$, holding $C_{t}$ constant, is $U_{C N}<0$, and the necessary and sufficient condition is $\frac{U_{N N}}{U_{N}}>\frac{U_{C N}}{U_{C}}$.
} 


\section{References}

[1] Adolfson, M., Laséen, S., Lindé, J., Villani, M., 2007. Bayesian estimation of an open economy dsge model with incomplete pass-through. Journal of International Economics 72 , pp.481-511.

[2] Alvarez, F., Atkeson, A., Kehoe, P.J., 2002. Money, interest rates, and exchange rates with endogenously segmented markets. Journal of political Economy 110, pp.73-112.

[3] Alvarez, F., Atkeson, A., Kehoe, P.J., 2009. Time-varying risk, interest rates, and exchange rates in general equilibrium. The Review of Economic Studies 76, pp.851-878.

[4] Armington, P.S., 1969. A theory of demand for products distinguished by place of production. Staff Papers 16, pp.159-178.

[5] Bilson, J., 1981. The "speculative efficiency" hypothesis. The Journal of Business 54, pp.435-51.

[6] Broadbent, B., 2017. Brexit and the pound. Bank of England, Speech 23.

[7] Bruno, V., Shin, H.S., 2014. Cross-border banking and global liquidity. The Review of Economic Studies 82, pp.535-564.

[8] Durlauf, S.N., Blume, L., 2008. The new Palgrave dictionary of economics. volume 6. Palgrave Macmillan Basingstoke.

[9] Engel, C., 1996. The forward discount anomaly and the risk premium: A survey of recent evidence. Journal of empirical finance 3, pp.123-192.

[10] Engel, C., 2014. Exchange rates and interest parity, in: Handbook of international economics. volume 4, pp. pp.453-522.

[11] Fama, E.F., 1984. Forward and spot exchange rates. Journal of monetary economics 14, pp.319-338.

[12] Feenstra, R.C., Luck, P.A., Obstfeld, M., Russ, K.N., 2014. In Search of the Armington Elasticity. Working Paper 20063. National Bureau of Economic Research.

[13] Gabaix, X., Maggiori, M., 2015. International liquidity and exchange rate dynamics. The Quarterly Journal of Economics 130, pp.1369-1420.

[14] Gourieroux, C., Monfort, A., Renault, E., 1993. Indirect inference. Journal of applied econometrics 8 . 
[15] Iskrev, N., . Calibration and the estimation of macroeconomic models. Working Paper.ISEG-Lisbon School of Economics and Management, REM, Universidade de Lisboa .

[16] Kouri, P.J., 1976. The exchange rate and the balance of payments in the short run and in the long run: A monetary approach. The Scandinavian Journal of Economics , pp.280-304.

[17] Le, V.P.M., Meenagh, D., Minford, P., Wickens, M., 2011. How much nominal rigidity is there in the us economy? testing a new keynesian dsge model using indirect inference. Journal of Economic Dynamics and Control 35, pp.2078-2104.

[18] Le, V.P.M., Meenagh, D., Minford, P., Wickens, M., Xu, Y., 2016. Testing macro models by indirect inference: a survey for users. Open Economies Review 27, pp.1-38.

[19] Maggiori, M., Lettau, M., Weber, M., 2014. Conditional risk premia in currency markets and other asset classes. Journal of Financial Economics 114, pp.197-225.

[20] Meenagh, D., Minford, P., Nowell, E., Sofat, P., 2010. Can a real business cycle model without price and wage stickiness explain uk real exchange rate behaviour? Journal of International Money and Finance 29, pp.1131-1150.

[21] Meenagh, D., Minford, P., Nowell, E., Sofat, P., Srinivasan, N., 2009. Can the facts of uk inflation persistence be explained by nominal rigidity? Economic Modelling 26, pp.978992.

[22] Nasir, M.A., Morgan, J., 2018. Pre-brexit: The eu referendum as an illustration of the effects of uncertainty on the sterling exchange rate. Journal of Economic Studies 45, pp.910 921.

[23] Nasir, M.A., Simpson, J., 2018. Brexit associated sharp depreciation and implications for uks inflation and balance of payments. Journal of Economic Studies 45, pp.231-246.

[24] Obstfeld, M., Rogoff, K., 2000. The six major puzzles in international macroeconomics: is there a common cause? NBER Macroeconomics Annual 15, pp.339-390.

[25] Ozkan, F.G., Unsal, D.F., . On the use of monetary and macroprudential policies for small open economies. International Monetary Fund Working Paper .

[26] Plakandaras, V., Gupta, R., Wohar, M.E., 2016. The depreciation of the pound post-brexit: Could it have been predicted? Finance Research Letters 21, pp.206-213. 
[27] Schmitt-Grohe, S., Uribe, M., 2003. Closing small open economy models. Journal of International Economics 61, 163-185.

[28] Smets, F., Wouters, R., 2003. An estimated dynamic stochastic general equilibrium model of the euro area. Journal of the European economic association 1, 1123-1175.

[29] Smith, A.A., 1993. Estimating nonlinear time-series models using simulated vector autoregressions. Journal of Applied Econometrics 8.

[30] Uribe, M., Schmitt-Grohe, S., 2017. Open Economy Macroeconomics. Princeton University Press, Princeton, New Jersey.

[31] Whittard, D., 2012. The uk's external balance sheet-the international investment position. Office for National Statistics . 